Obere Extremität 2021 · 16:148-154 https://doi.org/10.1007/s11678-021-00633-0 Received: 18 November 2020

Accepted: 27 January 2021

Published online: 3 March 2021

(c) The Author(s) 2021

\author{
Milad Farkhondeh Fal' (D) - Marius Junker² • Jörn Kircher, \\ 'Department of Trauma and Orthopaedic Surgery, University Hospital Hamburg Eppendorf, Hamburg, \\ Germany \\ ${ }^{2}$ Orthopaedic University Hospital Friedrichsheim, Frankfurt/Main, Germany \\ ${ }^{3}$ Department of Shoulder and Elbow Surgery, ATOS Klinik Fleetinsel Hamburg, Hamburg, Germany \\ ${ }^{4}$ Medical Faculty, Heinrich-Heine-University Düsseldorf, Düsseldorf, Germany
}

\title{
Typical patterns of malalignment in the degenerative acromioclavicular joint
}

22]). This procedure can be performed either arthroscopically or open, with a clear preference for the arthroscopic technique, as it implies a lower risk of impairing the superior joint capsule.

Little is known about the pathophysiology of non-traumatic degenerative AC joint disease. In the authors' clinical practice, they have observed a frequent phenomenon. In a number of cases, the AC joint of affected patients seems to open up with an anterior angle and the first contact of both joint partners is at the posterior part. The objective of this study, therefore, is to investigate whether there is a typical pattern of $\mathrm{AC}$ joint degeneration in comparison to healthy subjects. The hypotheses are that: (1) The disease starts at the posterior part of the joint and (2) that this is accompanied by a typical pattern of malalignment of the joint surfaces.

\section{Materials and methods}

This is a retrospective monocentric diagnostic study in which healthy and affected subjects were investigated using magnetic resonance imaging (MRI) scans in the transverse plane in the period from July 2013 to December 2017. All patients signed informed consent before participation and the ethics committee approved the study (study number: 3429).

Inclusion criteria for group 1 were healthy adults with normal asymptomatic AC joints with no history of trauma and, in group 2, adult patients with symp- tomatic AC joints who underwent arthroscopic AC joint resection.

Exclusion criteria were all relevant pathologies or activities that affect the AC joint, such as history of trauma or previous surgery and overhead athletes.

On MRI scans in the transverse plane, the anterior, central, and posterior joint space width of the AC joints was measured. The AC angle was measured between two lines that are aligned with the joint surface of the acromion and the lateral clavicle, respectively (an anteriorly open angle defined with positive values; - Fig. 1a-c).

All measurements were independently performed by the first and second authors, in a blinded fashion, on a computer using specific picture archiving and communication system (PACS) software (dicomPACS View, Version 5.2.11, Oehm and Rehbein, Rostock, Germany). Average values were used for statistical analysis.

SPSS $^{\circledR}$ software (Version 25.0; IBM Corp., Armonk, NY, USA) was used for statistical analysis. Measurement values were reported as mean values \pm standard deviation (SD), median, value range, and $95 \%$ confidence intervals. The normality of data was tested by visual inspection using boxplots and scatterplots and statistically using the Kolmogorov-Smirnov and Shapiro-Wilk tests. As the normality assumption was uncertain in portions of the data, the U-test according to MannWhitney and the Wilcoxon rank test were used to compare means of both groups 

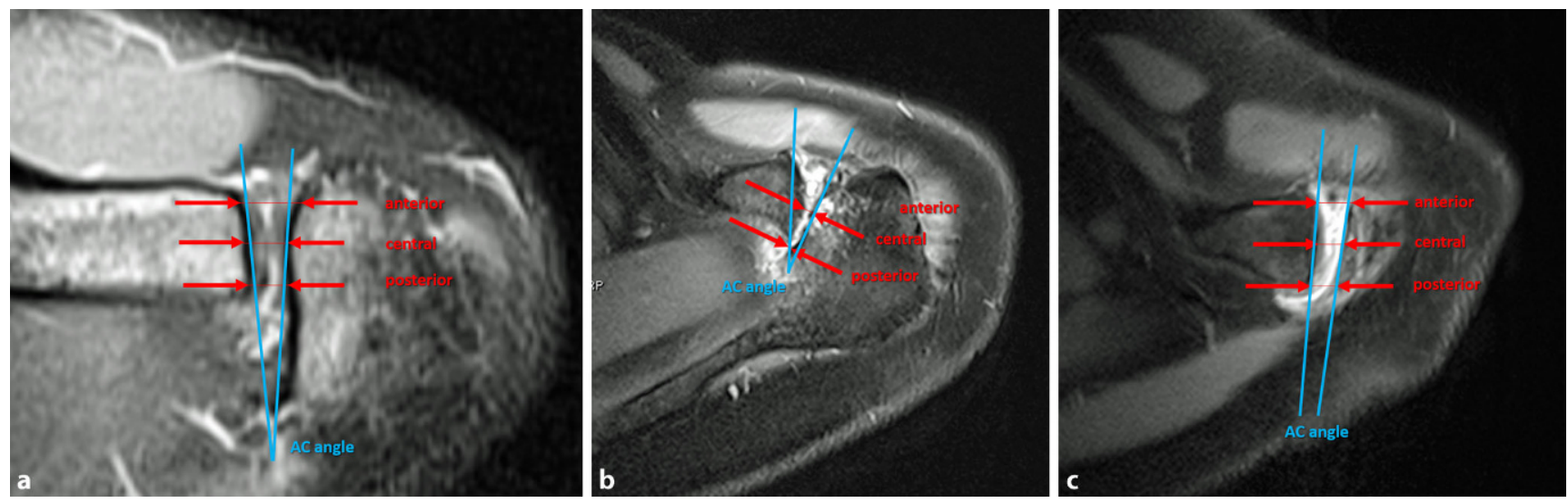

Fig. $1 \Delta$ Axial magnetic resonance imaging scans in the transvers plane. Measurement of the anterior, central, and posterior joint space (red) and the acromioclavicular $(A C)$ angle (light blue) in a physiological joint (a), an AC joint with advanced degenerative disease (b) with loss of joint space posterior, irregular joint surface and bone marrow edema, and an AC joint after distal clavicle resection (c) with normalization of all parameters

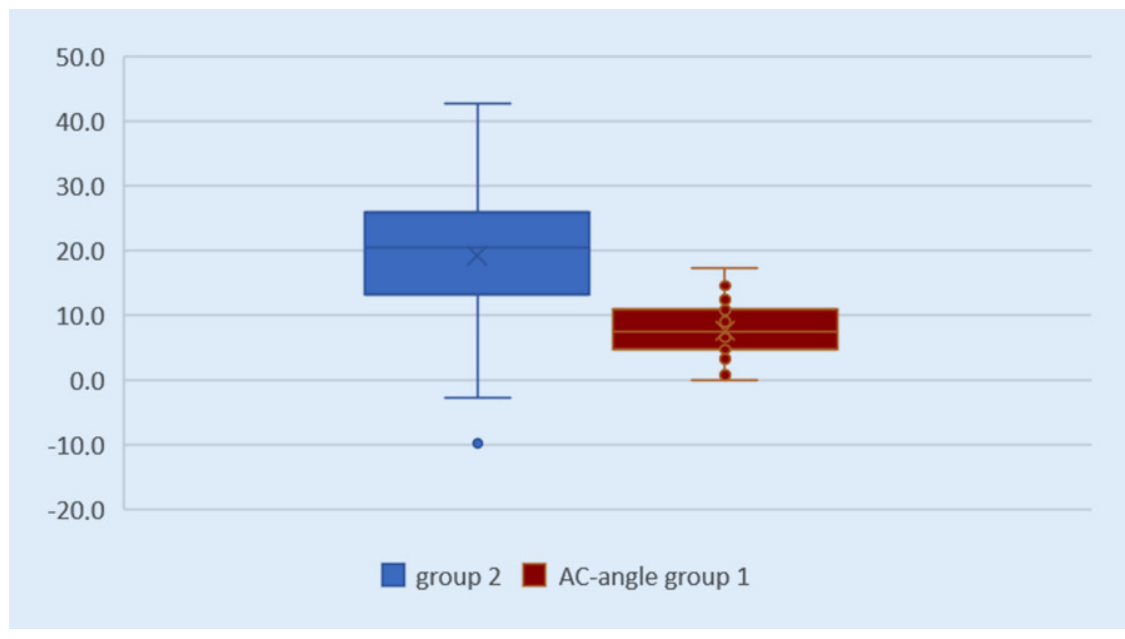

Fig. $2 \Delta$ Box plot illustrating acromioclavicular $(A C)$ angles in group 1 (red) and group 2 (blue) (x-axis) in degrees (y-axis) (horizontal lines display median and the first and third quartiles and vertical lines indicate maximum and minimum values)

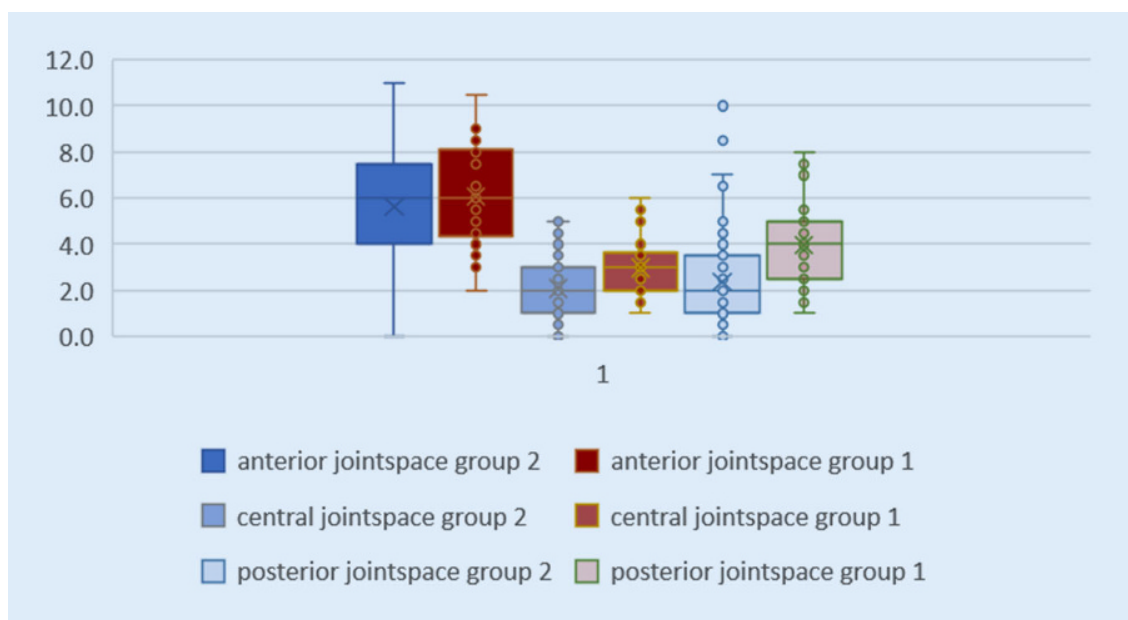

Fig. $3 \Delta$ Box plot illustrating joint space width in group 1 (red) and group 2 (blue) (x-axis) in $\mathrm{mm}$ (y-axis) (horizontal lines display median and the first and third quartiles and vertical lines indicate maximum and minimum values) and categorical data. The Spearman's rank test was used to perform correlation analysis.

Inter-observer reproducibility of the measurements was quantified with the intra-class correlation coefficient (ICC) using a pair-wise correlation model with absolute agreement. The ICC was classified from fair to excellent $[4,12]$. $P$ values below 0.05 were considered to be statistically significant.

\section{Results}

The mean age of patients in group 1 $(n=10$ female) was 38.6 years (SD 16.5; range 18.0-72.0) and in group $2(n=43$ females) 60.0 years (SD 11.0; range 18.2-84.5).

Significantly higher AC angles were observed in group 1 with 7.63 (range $0-17.2$ ) compared to $19.2^{\circ}$ in group 2 (range -9.8-42.7) $(p<0.001$; ○ Fig. 2; - Table 1).

The joint space width in both groups was significantly smaller in group 2 compared to group 1 for the central and posterior part $(p<0.001)$. These differences were also observed in a subgroup analysis for gender differences between the groups (• Table 2; • Fig. 3 ).

There were no gender differences within the groups except for slightly greater values for male patients for the anterior joint space width in group 2 $(6.1 \mathrm{~mm}$, range $0-11)$ compared to female patients in group $2(5.1 \mathrm{~mm}$, range $0-9)(p=0.033$; - Table 3$)$. 
Obere Extremität 2021 · 16:148-154 https://doi.org/10.1007/s11678-021-00633-0

(c) The Author(s) 2021

M. Farkhondeh Fal · M. Junker · J. Kircher

\section{Typical patterns of malalignment in the degenerative acromioclavicular joint}

\section{Abstract}

Introduction. Although arthroscopic acromioclavicular (AC) joint resection is a frequently performed procedure, the pathophysiology of non-traumatic AC joint degeneration is still unclear. The purpose of this study was to investigate whether non-traumatic AC joint degeneration shows a typical pattern and whether it starts at the posterior part of the joint with malalignment of the articular surfaces.

Materials and methods. In a retrospective monocentric diagnostic study, healthy and affected subjects were investigated using $\mathrm{T} 2$ magnet resonance imaging (MRI) scans in the transverse plane. Group 1 included 30 healthy asymptomatic adults with no history of trauma (mean age, 38.6 years). In group 2, 90 patients with symptomatic $A C$ joints who underwent arthroscopic $A C$ joint resection were included (mean age, 60.0 years). All patients with relevant pathologies that affect the $\mathrm{AC}$ joint were excluded. Malalignment was defined as posterior joint space smaller than $2 \mathrm{~mm}$ in conjunction with an $\mathrm{AC}$ angle lower than $12^{\circ}$.

Results. The measured values were (mean group 1 in $\mathrm{mm}$; mean group 2 in $\mathrm{mm} ; p$ value): anterior joint space $(6.07 ; 5.63 ; 0.50)$, central joint space $(2.97 ; 2.09 ; 0.001)$, and posterior joint space $(3.97 ; 2.38 ; 0,001), A C$ angle $(7.63 ; 19.2 ; 0.001)$. In group $1, n=24$ $(80 \%)$ of subjects showed aligned AC joints, whereas in group 2 , only $n=11(12.2 \%)$ of joints were aligned $(p<0.001)$. Increasing age correlated significantly with malalignment $(r=0.21, p=0.021)$.

Conclusions. Patients with symptomatic degenerative changes of the $A C$ joint show a typical pattern of anterior opening of the joint with early contact of the posterior joint surfaces in contrast to healthy subjects. Increasing age influences this effect.

Keywords

Acromioclavicular joint · Alignment . Joint space - Degenerative joint disease . Osteoarthritis

\section{Typische Fehlstellungsmuster bei Akromioklavikulargelenkdegeneration}

\section{Zusammenfassung}

Hintergrund. Obwohl die arthroskopische akromioklavikuläre (AK) Gelenkresektion häufig durchgeführt wird, ist die Pathophysiologie der nichttraumatischen AC-Gelenkdegeneration noch unklar. In der vorliegenden Studie wurde untersucht, ob die nichttraumatische AK-Gelenkdegeneration ein typisches Muster zeigt und ob sie am hinteren Teil des Gelenks mit einer Fehlstellung der Gelenkflächen beginnt.

Material und Methoden. $n$ einer retrospektivmonozentrischen Diagnostikstudie wurden gesunde und symptomatische Probanden mithilfe von T2-Magnetresonanztomographien (MRT) in der Transversalebene untersucht. Gruppe 1 umfasste 30 gesunde asymptomatische Erwachsene ohne Trauma in der Vorgeschichte (Durchschnittsalter
38,6 Jahre). In Gruppe 2 wurden 90 Patienten mit symptomatischen AK-Gelenken eingeschlossen, bei denen eine arthroskopische AK-Gelenkresektion durchgeführt wurde (Durchschnittsalter 60,0 Jahre). Alle Patienten mit relevanten Störungen des AC-Gelenks wurden ausgeschlossen. Eine Fehlstellung wurde definiert als Verringerung des hinteren Gelenkspalts $<2 \mathrm{~mm}$ in Verbindung mit einem AK-Winkel $<12^{\circ}$.

Ergebnisse. Die gemessenen Werte waren (Mittelwert in mm Gruppe 1; Mittelwert in mm Gruppe 2; $p$-Wert): vorderer Gelenkspalt $(6,07 ; 5,63 ; 0,50)$, zentraler Gelenkspalt $(2,97$; $2,09 ; 0,001)$, hinterer Gelenkspalt $(3,97 ; 2,38$; $0,001)$ und AK-Winkel $\left(7,63^{\circ} ; 19,2^{\circ} ; 0,001\right)$. In Gruppe 1 hatten $n=24(80 \%)$ der Probanden ein korrekt ausgerichtetes AK-Gelenk, in
Gruppe 2 war dies lediglich bei $n=11$ $(12,2 \%)$ der Fall $(p<0.001)$. Es fand sich eine signifikante Korrelation zwischen steigendem Alter und Fehlstellung $(r=0,21, p=0,021)$. Schlussfolgerung. Patienten mit symptomatischen degenerativen Veränderungen des AK-Gelenks zeigten ein typisches Muster der vorderen Gelenköffnung mit frühem Kontakt der hinteren Gelenkflächen verglichen mit gesunden Probanden. Das Alter beeinflusst diesen Effekt.

\section{Schlüsselwörter}

Akromioklavikulargelenk · Ausrichtung · Gelenkspalt · Degenerative Gelenkerkrankung . Arthrose
The interrater reliability (intraclass correlation coefficient, ICC) showed moderate to good values with better agreement in the control group $(\mathrm{r}=0.575$ to 0.744$)$ compared to the affected group ( $r=0.342$ to 0.624 ; $\bullet$ Table 4 ).

Age was found to be significantly correlated for the AC angle with decreasing values with increasing age $(r=-0.319$, $p=0.002)$ and for the anterior joint space $(\mathrm{r}=-0.219, p=0.038)$ only in group 2 . All other measured items were not correlated with age (• Table 5).
Malalignment of the AC joint was defined as a posterior joint space $<2 \mathrm{~mm}$ and an AC angle $<12^{\circ}$. The analysis of all patients in terms of alignment showed that only $n=11(12 \%)$ patients showed normal alignment of the AC joint in group 2 compared to $n=24(80 \%)$ patients in group 1 (• Table 6).

\section{Discussion}

The most striking result of this study is the observation of a typical pattern of AC joint degeneration with an increase of the
$\mathrm{AC}$ angle and reduction of the posterior joint space width with early contact of the acromion and clavicle that is responsible for the painful symptoms in affected patients. Edelson et al. described a typical pattern of changes at the acromion in advanced degenerative changes of the $\mathrm{AC}$ joint with elongation of the joint facet in the sagittal plane principally in the posterior aspect of the acromial facet [7]. This is confirmed by the present results that the posterior contact of the distal clavicle with the acromial joint facet is a typical phenomenon in the affected pa- 
Table 1 Measured values of acromioclavicular ( $A C$ ) angle (in degrees), anterior, central, and posterior joint space (in $\mathrm{mm}$ ) for group 2 (control) (mean, standard deviation [SD], minimum [Min], maximum [Max]). Level of significance, $p<0.05$ (significant values bold)

\section{Control}

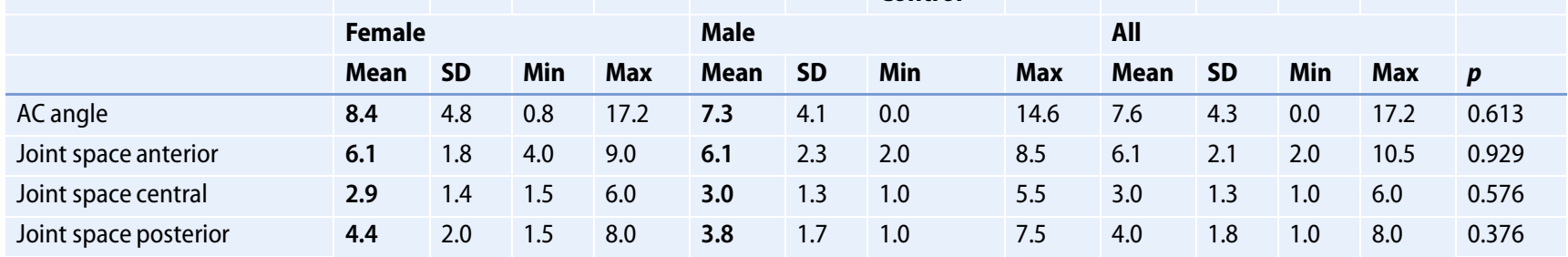

Table 2 Comparison of mean values (Mann-Whitney $U$ test) of group 1 (control), group 2 (af fected), and pooled data (all) regarding gender differences for acromioclavicular ( $A C$ ) angle, anterior, central, and posterior joint space. Level of significance $p<0.05$ (significant values bold)

\begin{tabular}{l|lll} 
& \multicolumn{2}{c}{ Control vs. affected } & All \\
\hline AC angle & Female & Male & 0.000 \\
\hline Joint space anterior & 0.002 & 0.000 & 0.500 \\
\hline Joint space central & 0.254 & 0.901 & 0.001 \\
Joint space posterior & 0.057 & 0.012 & 0.000
\end{tabular}

tient group. It appears to be logical that, with time and continued overload accompanied by osteophyte formation in conjunction with the deformation of the bony surface, flattening of the joint surface and extension in the posterior part occurs.

This phenomenon has not been studied as yet. One explanation is the altered kinematics of the healthy scapulothoracic rhythm. This not only stresses the AC joint, but also brings the rotator cuff in conflict with the scapula, which finds its correlate in the frequently observed coexistence of both pathologies in a number of patients $[3,5]$. This can be either dynamic or static and have a variety of possible effects. Frequently observed are inflexibility and stiffness of the muscles attached to the coracoid process (short head of biceps and pectoralis minor muscle) in conjunction with weakness of the muscles attached to the medial border of the scapula at the back (lower trapezius, rhomboid, and anterior serratus muscle) with loss of the stabilization effect to scapula to the thorax $[10,11]$. Additionally, a change of posture and an either dynamic (modern lifestyle with sitting, working at desks, and computers, etc.) or static (degenerative changes of the thoracic spine) increasing hyperkyphosis of the thoracic spine amplify the aforementioned effects [9, 28]. The protracted scapula pushes the distal clavicle forward, but the clavicle cannot follow this route of motion since it is fixed at the sternoclavicular joint where the majority of clavicle motion occurs [19, 22, 27]. Thus, the entire clavicle can only rotate forward in a part of a circle with its length being the radius and the sternoclavicular joint being the center of rotation.

This can result in malalignment of the joint surfaces with an opening AC angle and contact of the posterior parts of the clavicle and acromion (• Fig. 4).

The authors are not aware of any other study assessing the morphologic changes of degenerative AC joint disease in the axial plane and describing the joint space width in asymptomatic adult subjects [23].

Petersson et al. assessed the AC joint space in 151 patients on anteroposterior radiographs on plain films with a ruler [18]. They observed a decrease of the joint space with increasing age, but did not describe a statistical test for it. This is in contrast to the present study, in which no correlation of joint space width with increasing age was found for all patients and only a weak negative correlation was found for the anterior joint space in the affected group. This effect can be explained by a bias in patient selection in both studies. Petersson et al. do not provide any information on the clinical situation of the included patients (symptomatic vs. asymptomatic) and in the present study only 11 patients showed a pattern of joint degeneration with global joint space reduction that is too small to calculate a correlation with age.

Nicholson et al. also found an increasing number of AC joints with degenerative changes with increasing age in an analysis of 420 scapulae, but in contrast to the present study, the patient population consisted of many elderly patients. Additionally, the authors did not assess the joint space width, but made a visual judgment based on the formation of osteophytes, erosion of the subchondral bone, or the presence of eburnated bone [17].

The normal acromioclavicular joint space width is reported to be $1-3 \mathrm{~mm}$ [29] in a study by Zanca and 3.1 \pm 0.8 by Petersson [18] in the frontal plane on anteroposterior radiographs. One should note that many AC joints show a complex three-dimensional orientation (oblique in the frontal and axial plane) with individual variations, and the radiograph is the sum of overlap of these structures [8]. Therefore, it becomes highly likely that a distinct measurement on axial MRI scans without overlap results in higher absolute values.

It has been shown that, although advanced degenerative changes can be well visualized on anteroposterior radiography, smaller changes cannot be depicted [25]. In fact, the authors were able to show that, in a number of cases, the affected AC joints show a tendency to open up the anterior joint space and the $\mathrm{AC}$ angle anteriorly, which could easily be mistaken for a normal joint space on anteroposterior radiographs.

The aforementioned pathomechanism of a dynamic process starting with disturbed scapulothoracic motion leading to a typical pattern of AC joint degen- 
Table 3 Measured values of acromioclavicular ( $A C$ ) angle (in degrees), anterior, central, and posterior joint space (in mm) for group 2 (affected) (mean, standard deviation [SD], minimum [Min], maximum [Max]). Level of significance $p<0.05$ (significant values bold)

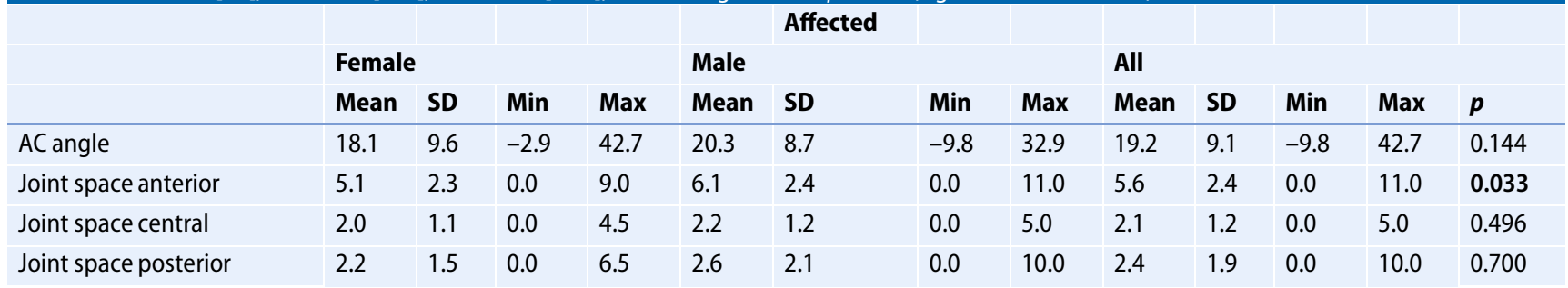

Table 4 Interrater reliability between (rank correlation coefficient r according to Spearman and Kendall) the measurements in group 1 (control) and group 2 (affected) for acromioclavicular (AC) angle, anterior, central, and posterior joint space. Level of significance $p<0.05$ (significant values bold). Values less than 0.5 were seen as poor, $0.5-0.75$ moderate, $0.75-0.9$ good, and values above 0.9 indicate excellent reliability

\begin{tabular}{|c|c|c|c|c|}
\hline & \multicolumn{2}{|l|}{ Control } & \multicolumn{2}{|l|}{ Affected } \\
\hline & $\mathbf{r}$ & $\boldsymbol{p}$ & $\mathbf{r}$ & $\boldsymbol{p}$ \\
\hline AC angle & 0.625 & 0.001 & 0.342 & 0.001 \\
\hline Joint space anterior & 0.744 & 0.001 & 0.624 & 0.001 \\
\hline Joint space central & 0.575 & 0.001 & 0.566 & 0.001 \\
\hline Joint space posterior & 0.705 & 0.001 & 0.473 & 0.001 \\
\hline
\end{tabular}

Table 5 Coefficient of correlation ( $r$ ) according to Spearman of age with acromioclavicular (AC) angle, anterior, central, and posterior joint space for group 1 (control) and group 2 (affected) and pooled data (all). Level of significance $p<0.05$ (significant values bold)

\begin{tabular}{lllllllll} 
& Control & & Affected & & All & \\
& r & $\boldsymbol{p}$ & $\mathbf{r}$ & $\boldsymbol{p}$ & $\mathbf{r}$ & $\boldsymbol{p}$ \\
\hline AC angle & 0.061 & 0.750 & -0.319 & $\mathbf{0 . 0 0 2}$ & 0.107 & 0.243 \\
Joint space anterior & 0.075 & 0.694 & -0.219 & $\mathbf{0 . 0 3 8}$ & -0.170 & 0.064 \\
\hline Joint space central & -0.710 & 0.710 & 0.058 & 0.586 & -0.144 & 0.118 \\
\hline Joint space posterior & 0.129 & 0.498 & 0.194 & 0.067 & -0.094 & 0.309
\end{tabular}

Table 6 Number of patients (absolute number $n$, percent of all patients in group \%) in group 1 (control) and group 2 (affected). Malalignment defined as acromioclavicular angle $<12^{\circ}$, posterior joint space width $<2 \mathrm{~mm}$

\begin{tabular}{llll} 
Group & Alignment & $\boldsymbol{n}$ & $\%$ \\
\hline Control & Aligned & 24 & 80.0 \\
Control & Malaligned & 6 & 20.0 \\
Affected & Aligned & 11 & 12.2 \\
Affected & Malaligned & 79 & 87.8
\end{tabular}

eration is only one possible explanation for symptomatic AC joint involvement. Direct trauma of the joint, such as in collision athletes, instability, malalignment, and degenerative changes after traumatic AC joint separation, among others, are possible causes of early joint destruction and pain. Further studies are necessary to work out more precisely possible determinants of AC joint degeneration, thereby allowing a better understanding of the disease and more specific therapy.

\section{Limitations}

There are some limitations that need to be noted. The control group consisted of 30 asymptomatic patients. Since degenerative AC joints can remain asymptomatic especially in early phases, there is a potential selection bias [24]. A selection bias also is likely for group 2, since the decision for arthroscopic AC joint resection in this study is a clinical one based on clinical examination, history of complaints and conservative therapy, psychological burden, and ra- diologic signs of joint degeneration and not on radiologic signs alone.

The measurement of the distances and angles is subject to relatively high variation, as expressed by the assessment of intraobserver reliability (• Table 3 ). This is due to the fact that the joint itself is comparatively small, the resolution on MRI scans limited, and the landmarks sometimes difficult to identify. This is aggravated by the fact that a number of patients present with a lateral clavicle joint surface that is not plane but convex or oblique, which makes identification especially of the anterior border of the joint difficult $[1,5]$.

The data were measured on MRI scans from different institutions and different scanners $(1.5 \mathrm{~T}$ and $3 \mathrm{~T})$. Although the scanning protocols are standardized, small variations must be assumed in the predefinition of landmarks for the scanning by each radiographer.

\section{Conclusion}

This study was able to identify a typical pattern of degenerative disease of the AC joint that starts at the posterior part of the joint in the axial plane along with anterior opening of the joint due to malalignment of the clavicle in relation to the acromion. The clinical impact is that, in the case of surgical treatment, particular attention should be paid to the posterior part of the joint.

\section{Corresponding address}

\section{Milad Farkhondeh Fal, M.D.}

Department of Trauma and Orthopaedic Surgery, University Hospital Hamburg Eppendorf

Martinistr. 52, 20246 Hamburg, Germany

farkhondehfal.milad@gmail.com 


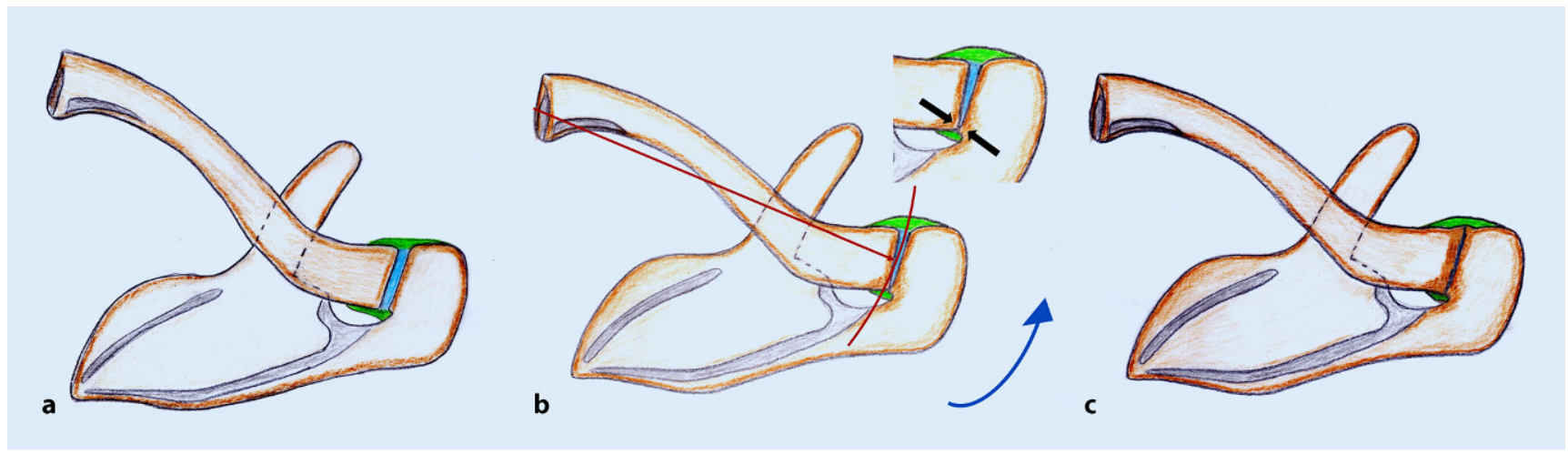

Fig. $4 \Delta$ The scapula and clavicle in the transverse plane in a normal situation (a) with normal joint space and articular cartilage (light blue). Protraction of the scapula leads to malalignment of the joint surface (blue arrow) (b) with loss of posterior articular cartilage and strain to the anterior capsule (green). The lateral clavicle cannot move forward parallel with its joint surface in regard to the acromion, but only rotate on a radius around the center of the sterno-clavicular joint (red arrowand sector of a circle) as a fixpoint. Endstage disease (c) is characterized by a complete loss of joint space, irregular joint surfaces, and formation of osteophytes

Author Contribution. Research design: JK, MFF, MJ; acquisition, analysis, or interpretation of data: JK, MJ, MFF; drafting of the paper or its critical revision: JK, MFF; approval of the submitted and final versions: JK, MFF, MJ

Funding. Open Access funding enabled and organized by Projekt DEAL.

\section{Compliance with ethical guidelines}

Conflict of interest. M. Farkhondeh Fal, M. Junker, and J. Kircher declare that they have no competing interests.

For this article no studies with human participants or animals were performed by any of the authors. All studies mentioned were in accordance with the ethical standards indicated in each case. The study was approved by the Ethics committee. All authors have read and approved the final submitted manuscript.

Open Access. This article is licensed under a Creative Commons Attribution 4.0 International License, which permits use, sharing, adaptation, distribution and reproduction in any medium or format, as long as you give appropriate credit to the original author(s) and the source, provide a link to the Creative Commons licence, and indicate if changes were made. The images or other third party material in this article are included in the article's Creative Commons licence, unless indicated otherwise in a credit line to the material. If material is not included in the article's Creative Commons licence and your intended use is not permitted by statutory regulation or exceeds the permitted use, you will need to obtain permission directly from the copyright holder. To view a copy of this licence, visit http://creativecommons.org/licenses/by/4.0/.

\section{References}

1. Barth J, Boutsiadis A, Narbona P et al (2017) The anterior borders of the clavicle and the acromion are not always aligned in the intact acromioclavicular joint: a cadaveric study. JShoulder Elbow Surg 26(7):1121-1127

2. Bergfeld JA, Andrish JT, Clancy WG (1978) Evaluation of the acromioclavicular joint following first- and second-degree sprains. Am J Sports Med 6(4):153-159

3. Chen AL, Rokito AS, Zuckerman JD (2003) The role of the acromioclavicular joint in impingement syndrome. Clin Sports Med 22(2):343-357

4. Cicchetti C (1994) Guidelines, criteria, and rules of thumb for evaluating normed and standardized assessment instruments in psychology. Psychol Assess 6(4):284-290

5. Colegate-Stone T, Allom R, Singh R, Elias DA, Standring S, Sinha J (2010) Classification of the morphology of the acromioclavicular joint using cadaveric and radiological analysis. J Bone Joint Surg Br 92(5):743-746

6. Depalma AF (1949) Variational anatomy and degenerative lesions of the shoulder joint. Instr Course Lcet 6:255-281

7. Edelson JG (1996) Patterns of degenerative change in the acromioclavicular joint. J Bone Joint Surg Br 78(2):242-243

8. Edelson JG, Taitz C (1992) Anatomy of the coracoacromial arch. Relation to degeneration of the acromion. JBone Joint Surg Br 74(4):589-594

9. Endo K, Yukata K, Yasui N (2004) Influence of age on scapulo-thoracic orientation. Clin Biomech 19(10):1009-1013

10. Kibler WB, Ludewig PM, McClure PW, Michener LA, Bak K, Sciascia AD (2013) Clinical implications of scapular dyskinesis in shoulder injury: the 2013 consensus statement from the 'Scapular Summit. BrJ Sports Med 47(14):877-885

11. Kibler WB, Sciascia A, Wilkes T (2012) Scapular dyskinesis and its relation to shoulder injury. J Am Acad Orthop Surg 20(6):364-372

12. Koo TK, Li MY (2016) A guideline of selecting and reporting Intraclass correlation coefficients for reliability research. J Chiropr Med 15(2):155-163

13. Lehtinen JT, Lehto MU, Kaarela K, Kautiainen HJ, BeltEA, Kauppi MJ (1999) Radiographic joint space in rheumatoid acromioclavicular joints: a 15 year prospective follow-up study in 74 patients. Rheumatology 38(11):1104-1107

14. Mall NA, Foley E, Chalmers PN, Cole BJ, Romeo AA, Bach BR Jr. (2013) Degenerative joint disease of the acromioclavicular joint: a review. Am J Sports Med 41(11):2684-2692

15. Mazzocca AD, Arciero RA, Bicos J (2007) Evaluation and treatment of acromioclavicular joint injuries. Am J Sports Med 35(2):316-329

16. Needell SD, Zlatkin MB, Sher JS, Murphy BJ, Uribe JW (1996) MR imaging of the rotator cuff: peritendinous and bone abnormalities in an asymptomatic population. AJR Am J Roentgenol 166(4):863-867

17. Nicholson GP, Goodman DA, Flatow EL, Bigliani LU (1996) The acromion: morphologic condition and age-related changes. A study of 420 scapulas. JShoulderElbow Surg 5(1):1-11

18. Petersson CJ, Redlund-Johnell I (1983) Radiographic joint space in normal acromioclavicular joints. Acta Orthop Scand 54(3):431-433

19. Renfree KJ, Wright TW (2003) Anatomy and biomechanics of the acromioclavicular and sternoclavicular joints. Clin Sports Med 22(2):219-237

20. Riis RN, Øzeke R, Bjørklund UH, Aarsrud JO, Orlin JR (1996) Osteoarthrosis of the acromioclavicular joint, an underestimated cause of shoulder pain. JShoulderElbow Surg 5(2):S18

21. Rockwood CAJ, Young C (1990) Disorders of the acromioclavicular joint. In: Rockwood CAJ, Matsen FA (eds) The Shoulder. WB Saunders, Philadelphia, pp 483-553

22. Shaffer BS (1999) Painful conditions of the acromioclavicular joint. J Am Acad Orthop Surg 7(3):176-188

23. Shubin Stein BE, Ahmad CS, Pfaff CH, Bigliani LU, Levine WN (2006) A comparison of magnetic resonance imaging findings of the acromioclavicular joint in symptomatic versus asymptomatic patients. JShoulder Elbow Surg 15(1):56-59

24. Stein BE, Wiater JM, Pfaff HC, Bigliani LU, Levine WN (2001) Detection of acromioclavicular joint pathology in asymptomatic shoulders with magnetic resonance imaging. J Shoulder Elbow Surg 10(3):204-208

25. Stenlund B, Marions O, Engstrom KF, Goldie I (1988) Correlation of macroscopic osteoarthrotic changes and radiographic findings in the acromioclavicular joint. Acta Radiol 29(5):571-576

26. Taft TN, Wilson FC, Oglesby JW (1987) Dislocation of the acromioclavicular joint. An end-result study. JBone Joint Surg Am 69(7):1045-1051 


\section{Original Contribution}

27. Worcester JN Jr., Green DP (1968) Osteoarthritis of the acromioclavicular joint. Clin Orthop Relat Res 58:69-73

28. Yamamoto A, Takagishi K, Kobayashi T et al (2015) The impact of faulty posture on rotator cuff tears with and without symptoms. J Shoulder Elbow Surg 24(3):446-452

29. Zanca P (1971) Shoulder pain: involvement of the acromioclavicular joint. (Analysis of 1,000 cases). Am J Roentgenol Radium Ther Nucl Med 112(3):493-506 